\title{
Perfil epidemiológico de la influenza humana a H1N1
}

DOI: $10.46981 /$ sfjhv2n2-009

Received in: April 1st, 2021

Accepted in: May 31th, 2021

\section{Enrique Rojas Salazar \\ Médico Cirujano}

Facultad de Medicina Universidad Mayor de San Simón, Cochabamba-Bolivia Instituto de Investigaciones Biomédicas e Investigación Social IIBISMED - UMSS.

Dirección: Avenida Aniceto Arce 2876, Cochabamba-Bolivia

Correo electrónico: dr.rojas.enrique@gmail.com

\section{Rodrigo Uño Tala}

Médico Cirujano

Facultad de Medicina Universidad Mayor de San Simón, Cochabamba-Bolivia

Instituto de Investigaciones Biomédicas e Investigación Social IIBISMED - UMSS.

Dirección: Avenida Aniceto Arce 2876, Cochabamba-Bolivia

Correo electrónico: rodrisanty197@gmail.com

\section{Yercin Mamani Ortiz}

Doctorado en Salud Pública Universidad de Umea-Suecia, Magister en Ciencias de la Educación

Superior Universitaria.

Facultad de Medicina Universidad Mayor de San Simón, Cochabamba-Bolivia Instituto de Investigaciones Biomédicas e Investigación Social IIBISMED - UMSS.

Dirección: Avenida Aniceto Arce 2876, Cochabamba-Bolivia

Correo electrónico: yercin2003@ hotmail.com

\section{Betty Melgarejo}

Bioquímica, Msc. Inmunohematologia y Medicina Transfusional

Magister en Salud Pública

Servicio Departamental de Salud (SEDES) Cochabamba.

Dirección: Avenida Aniceto Arce 2876, Cochabamba-Bolivia

Correo electrónico: bemel10@yahoo.es

\section{Efrain Vallejo}

Médico Cirujano, Magister en Salud Pública

Servicio Departamental de Salud (SEDES) Cochabamba.

Responsable Unidad de Epidemiología SEDES Cochabamba

Dirección: Avenida Aniceto Arce 2876, Cochabamba-Bolivia

Correo electrónico: evallejo@yahoo.es

\section{Daniel Illanes Velarde}

Médico Cirujano, Magister en Salud Pública

Facultad de Medicina Universidad Mayor de San Simón, Cochabamba-Bolivia

Instituto de Investigaciones Biomédicas e Investigación Social IIBISMED - UMSS.

Dirección: Avenida Aniceto Arce 2876, Cochabamba-Bolivia

Correo electrónico: dillanes50@gmail.com 


\title{
Mayra Rocha Choque Médico Cirujano
}

Facultad de Medicina Universidad Mayor de San Simón, Cochabamba-Bolivia Instituto de Investigaciones Biomédicas e Investigación Social IIBISMED - UMSS.

Dirección: Avenida Aniceto Arce 2876, Cochabamba-Bolivia

Correo electrónico: mayrarocha6892@gmail.com

\section{RESUMEN}

Introducción: En junio de 2009, la Organización Mundial de la Salud alertó acerca de la pandemia debida al virus A (H1N1) que elevó la fase epidemiológica a 6, producto del grado de diseminación del virus pero no a la gravedad e impacto de la enfermedad, lo que depende de la vulnerabilidad de la población y la capacidad de respuesta sanitaria de cada región, país y continente respectivamente. Objetivo: analizar el perfil epidemiológico de la influenza A- H1N1 en el departamento de Cochabamba-Bolivia. Métodos: el presente estudio es de tipo observacional, descriptivo y de corte transversal, realizado en el departamento de Cochabamba, Bolivia mediante el análisis de todas las fichas epidemiológicas de los casos sospechosos durante las gestiones 2009 al 2014, con una muestra de 3655 fichas. Resultados: del total de casos sospechosos el 52\% fueron varones y el $48 \%$ mujeres, el grupo etario con mayor proporción fue el de los menores de 5 años con un $16 \%$, del total de casos sospechosos el $79 \%$ fueron negativos y solo el $21 \%$ fueron positivos, los síntomas más frecuentes fueron la tos presente en el $84 \%$ de los casos, la faringitis en el 78\%, la cefalea y la rinorrea en el $76 \%$. Conclusión: la prevalencia de Influenza Humana A H1 N1 en el departamento de Cochabamba, disminuyó progresivamente, existiendo un rebrote de la patología el 2014 con un aumento en el número de casos positivos y los casos de mortalidad.

Palabras clave: Influenza AH1N1, Pandemia, Virus, AH1N1, Bolivia.

\begin{abstract}
Introduction: In June 2009, the World Health Organization alerted about the pandemic due to Virus A (H1N1) that raised the epidemiological phase to 6, mainly due to the degree of spread of the virus but not for the severity or impact of the disease, which depends on the vulnerability of the population and the health response capacity in each region, country and continent respectively. Objective: Analyze the epidemiological profile of influenza A-H1N1 in Cochabamba, Bolivia Methods: This study is an observational, descriptive and cross-sectional study conducted at the Department of Cochabamba, using the analysis of all epidemiological records of suspected cases; during the years 2009 to 2014, with a sample of 3655 patients. Results: of all suspected cases, $52 \%$ were male and $48 \%$ female, the age group with the highest proportion was the children under 5 years with $16 \%$ of the total suspected cases, $79 \%$ were negative and only $21 \%$ were positive, the most common symptoms reported were cough present in $84 \%$ of cases, sore throat in $78 \%$, headache and rhinorrhea in $76 \%$. Conclusion: the prevalence of human influenza H1N1 at the Department of Cochabamba, decreased progressively, with a new outbreak of the disease in 2014 with an increase in the number of positive cases and mortality.
\end{abstract}

Keywords: Influenza H1N1, Pandemic, Virus, H1N1, Bolivia. 


\section{INTRODUCCIÓN}

La información sobre el comportamiento epidemiológico del virus y la clínica de las enfermedades, es indispensable para formular y emplear medidas de contención sanitaria, que coadyuven a mitigar su impacto en la salud pública de los estados.

La influenza es una enfermedad respiratoria viral aguda altamente transmisible de importancia mundial, que ha causado epidemias y pandemias por siglos ${ }^{1}$; El 15 y 17 de abril del 2009, se detectó un nuevo virus con una gran carga genómica de procedencia porcina capaz de infectar a humanos, el mismo que fue denominado tardíamente nuevo virus de la influenza $\mathrm{A} / \mathrm{H} 1 \mathrm{~N} 1$ siendo éste el que ha desencadenado la actual pandemia de influenza $\mathrm{AH} 1 \mathrm{~N} 1^{2}$. En junio de ese mismo año, la Organización Mundial de la Salud (OMS) alertó acerca de la pandemia debida al virus A (H1N1) que elevó la fase epidemiológica a 6 "pandemia" (que define extensión geográfica), esta acción se debido al grado de diseminación del virus pero no a la gravedad e impacto de la enfermedad, que depende de la vulnerabilidad de la población y la capacidad de respuesta sanitaria de cada región, país y continente. El responsable es un virus con combinación genética aviar, humana y porcina, y las manifestaciones clínicas van desde casos leves hasta la muerte ${ }^{2,3,4}$.

La tasa de letalidad de la enfermedad que inicialmente fue alta, ha pasado a ser baja, gracias al diagnóstico oportuno y el inicio de los tratamientos antivirales precozmente; sin embargo su evolución real es impredecible 5 .

La Influenza Humana A H1N1 es una enfermedad de vigilancia epidemiológica obligatoria y de notificación inmediata, para el que se desarrollaron varias estrategias de control y seguimiento por parte del Servicio Departamental de Salud del Departamento de Cochabamba Bolivia (SEDES Cbba.), debido a que es una patología de rápida evolución y puede ser transmitida por vía aérea.

Si bien ya existe una vacuna para su prevención y el tratamiento establecido por la OMS es efectiva en la mayor proporción de los casos, es necesario optimizar los mecanismo de vigilancia epidemiológica, siendo que no existen mecanismos locales para la evaluación interna y externa de los instrumentos, metodologías, técnicas de laboratorio y mucho menos del sistema de notificación de $\operatorname{casos}^{6-7}$.

Si bien se aplicaron varias estrategias para el control y la vigilancia epidemiológica de la Influenza Humana A H1N1, no existe una evaluación minuciosa sobre los resultados obtenidos por el mismo en estos 6 años de implementación, de manera que es importante contar con un reporte que pueda identificar los pro y contras de las intervenciones efectuadas, comenzando por la aplicación del sistema de vigilancia epidemiológica y su instrumento básico, la ficha epidemiológica ${ }^{5,7,8}$.

La importancia del presente trabajo radica en que nos permite contar con una visión general de la situación actual y el comportamiento epidemiológico a lo largo de los años, que permitirá proyectar 
nuevas intervenciones o afinar las existentes para erradicar esta patología de nuestro medio, además de permitirnos conocer el impacto que tuvo esta patología en nuestra ciudad con fines de proporcionar datos epidemiológicos.

El objetivo principal de la investigación es el de analizar el perfil epidemiológico de la influenza A- H1N1 en el departamento de Cochabamba, Bolivia; donde se reportaron casos sospechosos de influenza desde el año 2009 hasta el 2014, durante un seguimiento de 6 años; sirviendo para la generación de un Canal Endémico de Borman, específico para la Influenza A H1N1, de manera que permita prever el comportamiento epidemiológico en los futuros años.

\section{MATERIALES Y MÉTODOS}

Se realizó un estudio de tipo observacional, descriptivo de corte transversal, en base a las formularios de vigilancia epidemiológica centralizadas por el Servicio Departamental de Salud Cochabamba, mediante su Laboratorio de Referencia desde el inicio de la pandemia en 2009 hasta diciembre del 2014; ingresando en el estudio todos los casos notificados (sospechosos y confirmados), sistematizadas en una base de datos construida en base a los objetivos del estudio, excluyéndose aquellos formularios incompletos.

Ingresaron en el estudio 3655 formularios completos en los que se evaluaron la edad, sexo, patología de base y procedencia del paciente: la semana epidemiológica, cuadro clínico, prueba confirmatoria por Reacción en Cadena de la Polimerasa (PCR; por sus siglas en Ingles: Polymerase Phain Reaction) en base a las técnicas estandarizadas de la $\mathrm{OMS}^{9,10,11}$, y la notificación de fallecimiento; sistematizadas mediante el Software Microsoft Excel ${ }^{\circledR}$, para su posterior análisis; utilizándose métodos de estadística descriptiva y análisis epidemiológico para la presentación de los resultados; así como la construcción de un canal endémico en base a las incidencias de casos por semana epidemiológica durante los 5 primeros años. Se mantuvo el principio de confidencialidad utilizando solo el número de registro para la identificación de los sujetos de estudio, contándose con la aprobación del comité técnico de la unidad de epidemiología del SEDES-Cochabamba y la Responsable del Laboratorio de Referencia Departamental durante la gestión 2014, para la utilización de las fichas epidemiológicas.

\section{RESULTADOS}

Luego de analizados los datos se obtuvieron los siguientes resultados:

En la presentación del total de casos sospechosos $(n=3655)$, el 52\% $(n=1905)$ fueron varones y el $48 \% \quad(n=1750)$ fueron mujeres.

El grupo etario con mayor proporción de casos sospechosos fue en menores de 5 años con un $16 \%$ del total, $(n=585)$, seguido por el grupo comprendido entre 5 a 9 años con un $13 \%(n=475)$, y de 
10 a 14 años juntamente con los de 20 a 24 años, tuvieron un $11 \%$ ( $n=402$ casos cada uno), del total de casos sospechosos (Figura 1).

Figura 1 Representación porcentual de los casos sospechosos más frecuentes en relación al grupo etario

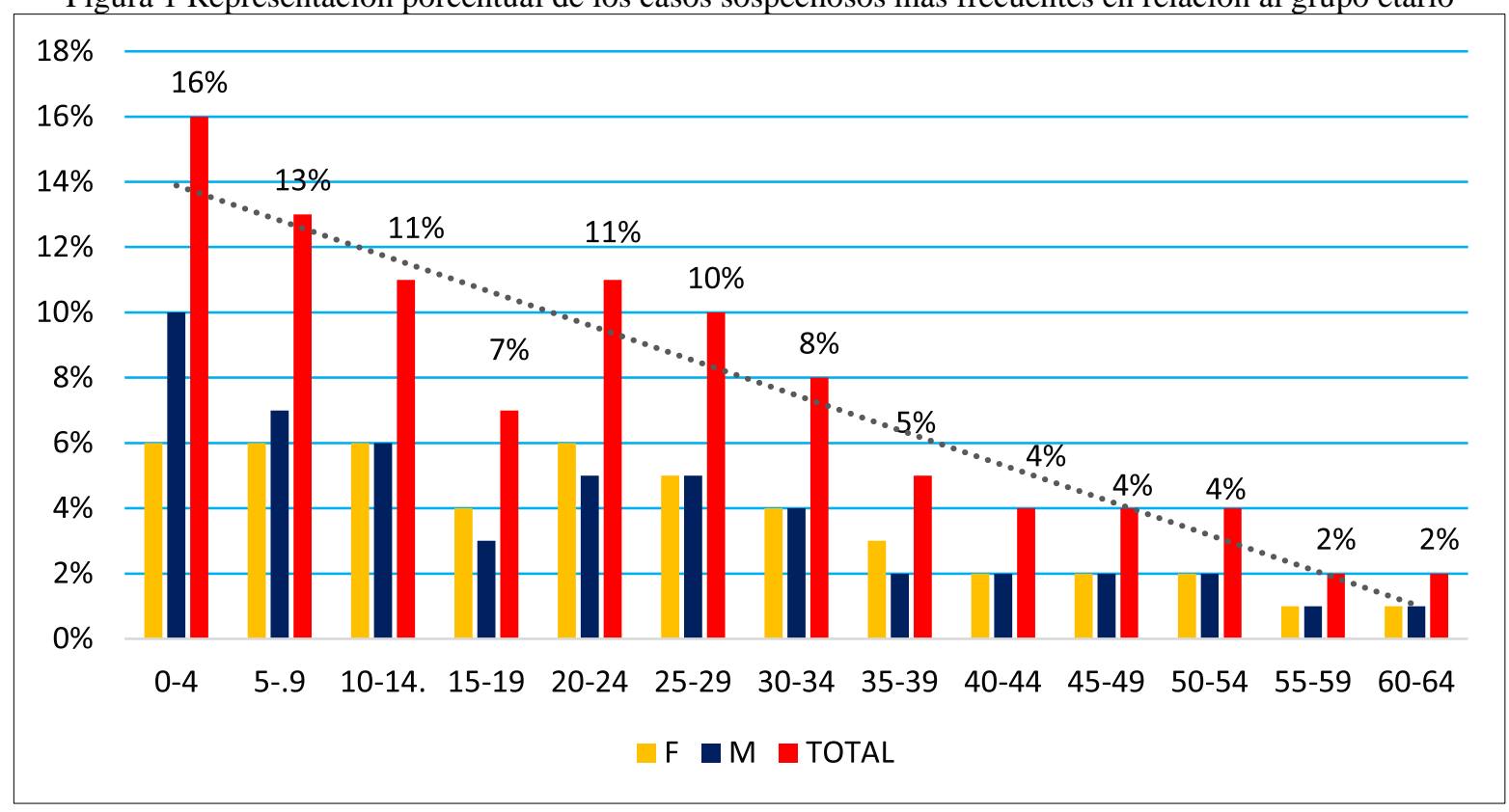

Fuente: Elaboración propia, en base a formularios de vigilancia epidemiológica Influenza A H1N1 SEDES CBBA.

En relación al número de casos sospechosos por año, en el 2009 tiene el mayor número con 1197 casos reportados, con una disminución progresiva de los mismos hasta el 2014 en el que sólo existieron 243 casos sospechosos reportados, del mismo modo el total de casos positivos fue descendiendo desde el 2009 con 251 casos positivos, 2010 con 141 casos positivos, 2011 con 83 casos positivos, 2012 con 46 casos positivos, 2013 con 16 casos positivos y se vuelve a generar un brote en el 2014 con 84 casos positivos (Figura 2). 
Figura 2 Número de casos sospechosos, positivos y fallecidos asociados a la Influenza A H1N1

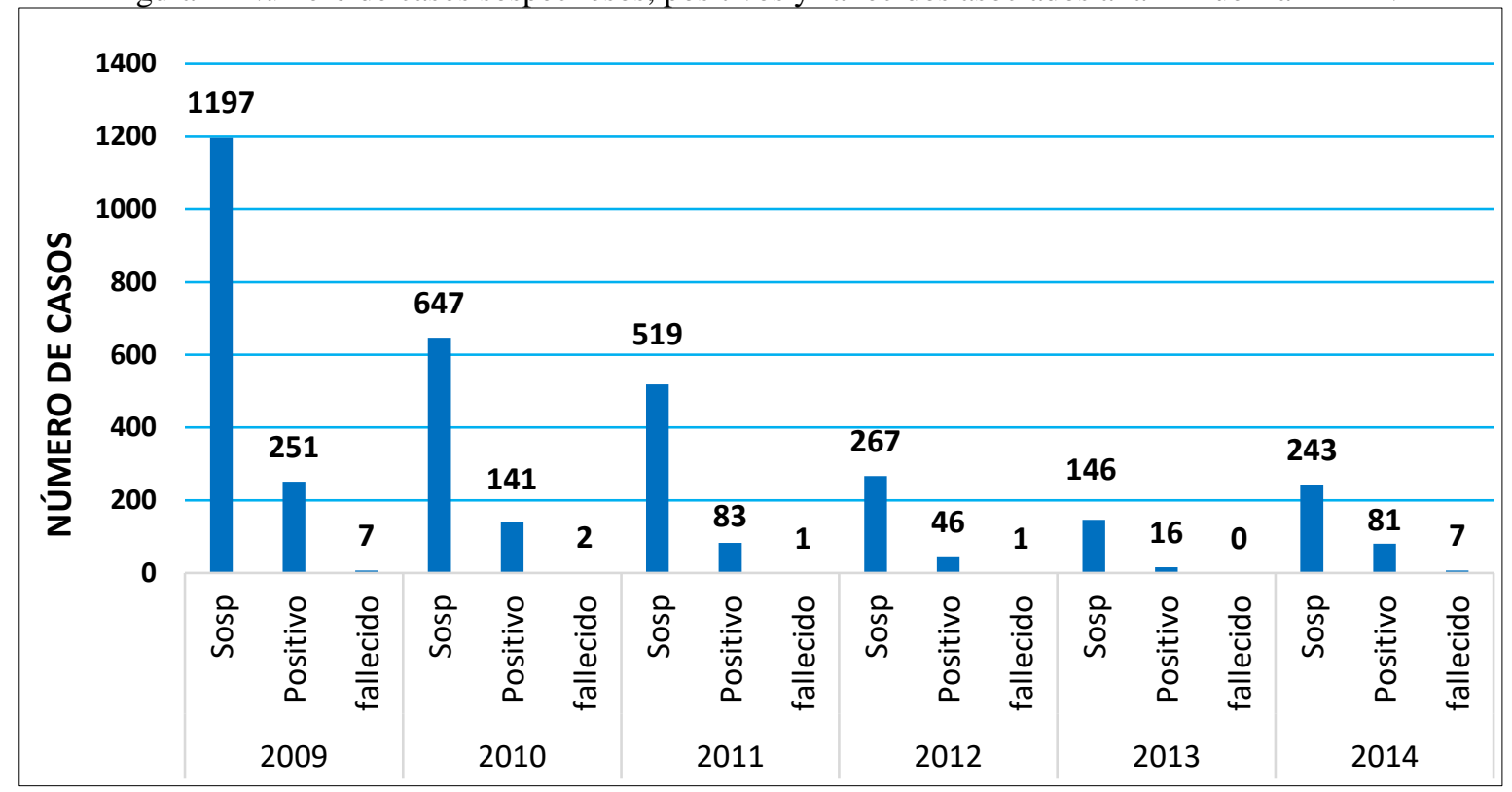

Fuente: Elaboración propia, en base a formularios de vigilancia epidemiológica Influenza A H1N1 SEDES CBBA

La mortalidad también disminuyo, de 251 casos en el año 2009 a 0 casos el 2013, pero el 2014 se volvieron a presentar 7 casos de pacientes fallecidos con Influenza Humana A H1N1, ya sea como causa principal o asociada. Ver cuadro N.- 3. Para hacer un mejor análisis de los pacientes fallecidos, la tasa de letalidad anual fue para el año 2009 de 2,7\%, el 2010 de 2,3\%, el 2012 de 2,1\%, el 2013 fue de $0 \%$ debido a que no se presentaron personas fallecidas en dicho año, y el 2014 fue el año con mayor tasa de letalidad con $8,6 \%$ ya que existieron 7 personas fallecidas de un total de 81 casos positivos (Figura 3).

Figura 3 Tasa de letalidad anual de la Influenza A H1N1

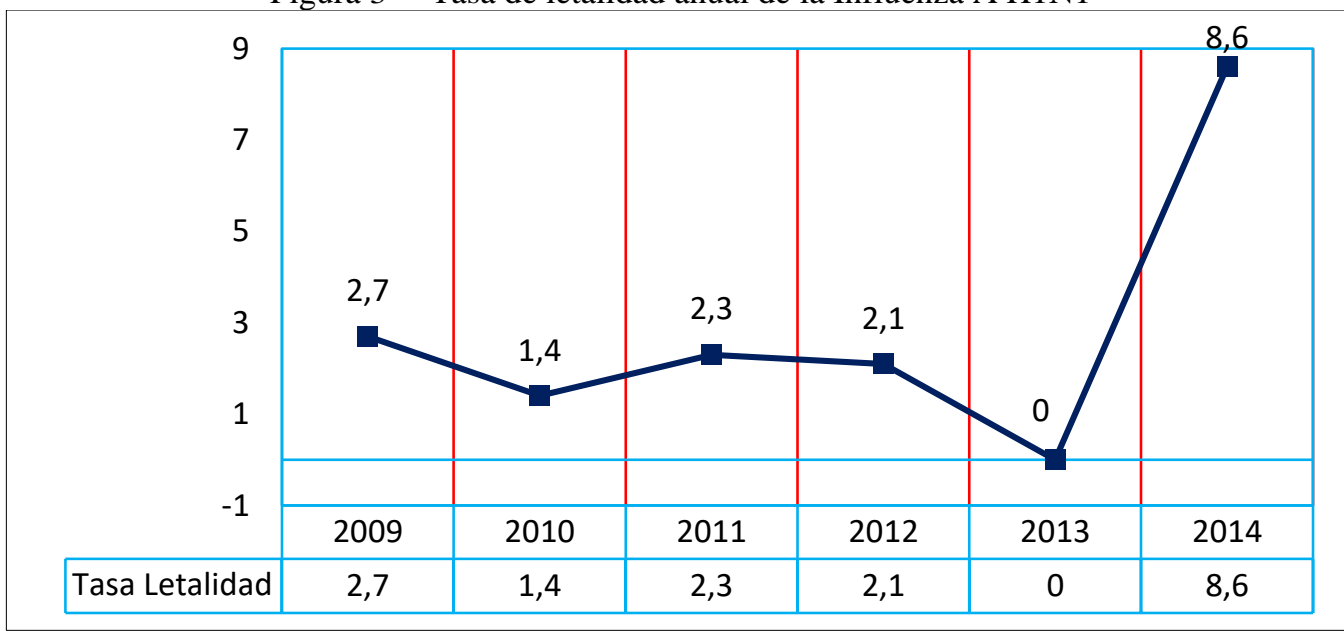

Fuente: Elaboración propia, en base a formularios de vigilancia epidemiológica Influenza A H1N1 SEDES CBBA 
Del total de casos sospechosos, el $79 \%$ fueron negativos y solo el $21 \%$ de los casos fueron positivos por la prueba de PCR en tiempo real (Tabla 2).

Tabla 2 Porcentaje de casos positivos por la prueba de PCR en tiempo real.

\begin{tabular}{|l|l|l|l|l|l|l|}
\hline CONFIRMACIÓN & \multicolumn{2}{l}{ Variables y Porcentajes } \\
\cline { 2 - 8 } DIAGNÓSTICA & F & $\mathbf{\%}$ & M & \% & Total general & \% \\
\hline NEGATIVO & 1510 & $\mathbf{4 1 \%}$ & 1384 & $\mathbf{3 8 \%}$ & $\mathbf{2 8 9 4}$ & $\mathbf{7 9 \%}$ \\
\hline POSITIVO & 377 & $\mathbf{1 0 \%}$ & 384 & $\mathbf{1 1 \%}$ & $\mathbf{7 6 1}$ & $\mathbf{2 1 \%}$ \\
\hline Total general & 1887 & $\mathbf{5 2 \%}$ & 1768 & $\mathbf{4 8 \%}$ & $\mathbf{3 6 5 5}$ & $\mathbf{1 0 0 \%}$ \\
\hline
\end{tabular}

Fuente: Elaboración propia, en base a formularios de vigilancia epidemiológica Influenza A H1N1 SEDES CBBA.

En relación anual el porcentaje de pacientes internados del número de casos positivos fue para el 2009 de 19\%, para el 2010 fue de 15\%, el 2011 fue 17\%, el 2012 fue de 17\%, los años con mayor porcentaje fueron el 2013 con $31 \%$, y el 2014 con $34 \%$ de pacientes internados del total de casos positivos (Figura 4).

Figura 4 Porcentaje pacientes internados del total de casos positivos presentados anualmente

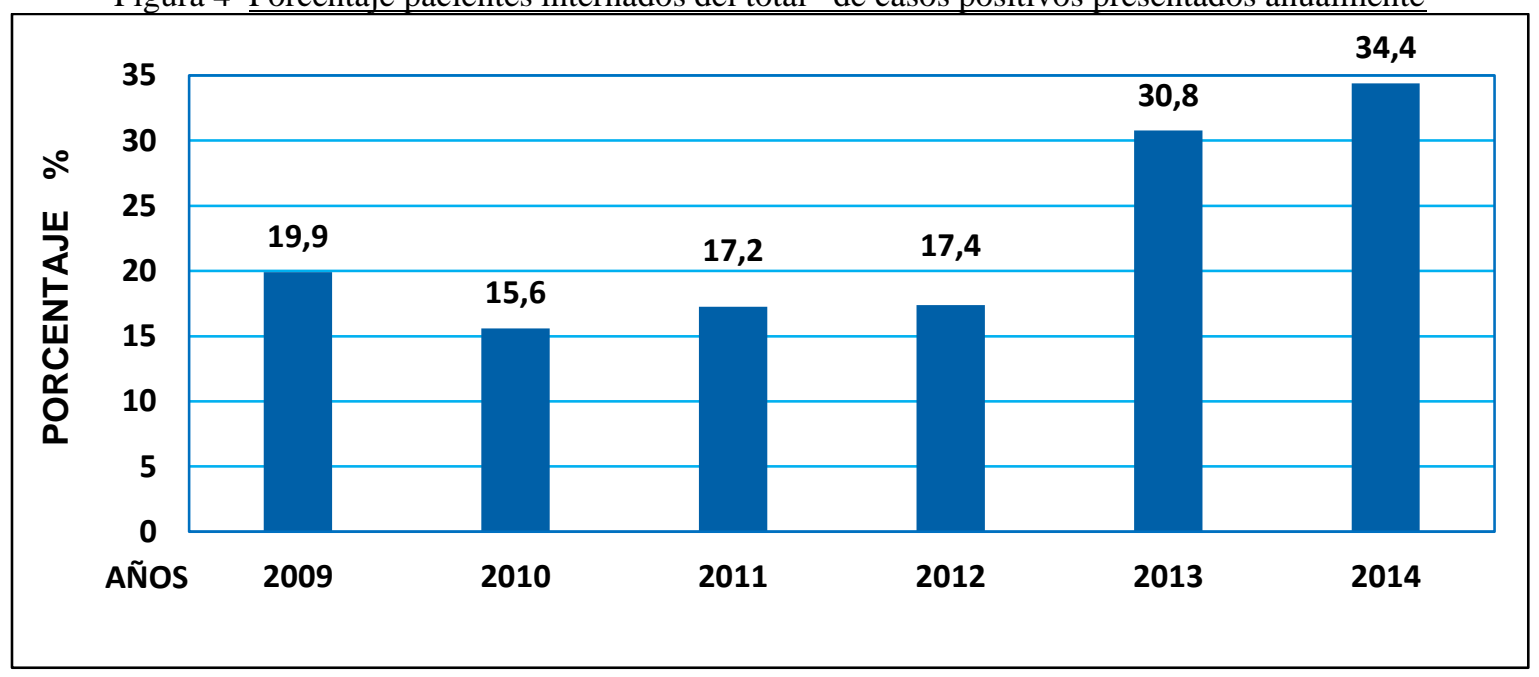

Fuente: Elaboración propia, en base a formularios de vigilancia epidemiológica Influenza A H1N1 SEDES CBBA..

Acorde al número promedio de casos positivos en relación a las semanas epidemiológicas pudimos determinar que los períodos comprendidos entre las semanas 23 a la 42 (junio, julio y agosto, septiembre, octubre) fueron los que tuvieron una mayor cantidad de casos positivos (Figura 5). 
Figura 5 Relación proporcional de la incidencia de casos por mes

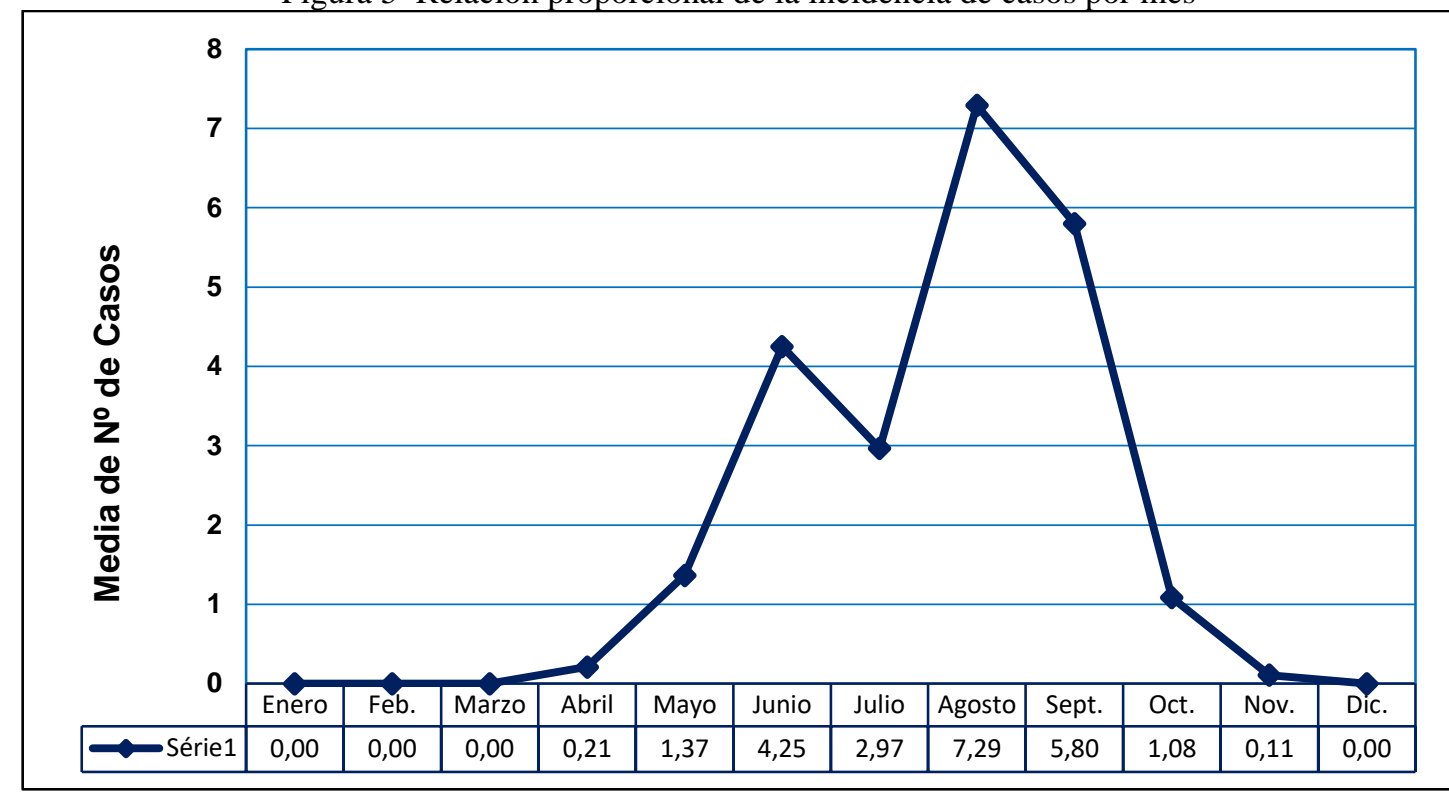

Fuente: Elaboración propia, en base a formularios de vigilancia epidemiológica Influenza A H1N1 SEDES CBBA.

Los síntomas más frecuentes al inicio del cuadro, fueron la tos en el $84 \%$ de los casos, la faringitis en el $78 \%$, la cefalea y la rinorrea en el $76 \%$ de los casos; siendo el menos frecuentes las erupciones cutáneas y taquipnea en menos del $4 \%$ de los casos sospechosos (Tabla 3).

Tabla 3 Porcentaje de la sintomatología presentada por todos casos sospechosos de influenza A H1N1

\begin{tabular}{|l|c|c|}
\hline SINTOMA & Número & Porcentaje \% \\
\hline Tos & 2538 & $84 \%$ \\
\hline Fiebre mayor a $38^{\circ} \mathrm{C}$ & 2364 & $79 \%$ \\
\hline Faringitis & 2347 & $78 \%$ \\
\hline Cefalea & 2299 & $76 \%$ \\
\hline Rinorrea & 2295 & $76 \%$ \\
\hline Mialgia & 1994 & $66 \%$ \\
\hline Astenia & 1963 & $65 \%$ \\
\hline Dolor de garganta & 1713 & $57 \%$ \\
\hline Conjuntivitis & 1020 & $34 \%$ \\
\hline Disnea & 979 & $33 \%$ \\
\hline Vómitos & 908 & $30 \%$ \\
\hline Bronquitis & 697 & $23 \%$ \\
\hline Diarrea & 549 & $18 \%$ \\
\hline Otitis & 529 & $18 \%$ \\
\hline Neumonía & 455 & $15 \%$ \\
\hline Adenopatías & 290 & $10 \%$ \\
\hline Erupciones & 115 & $4 \%$ \\
\hline Otros & 25 & $1 \%$ \\
\hline Taquipnea & 17 & $1 \%$ \\
\hline
\end{tabular}

Fuente: Elaboración propia, en base a formularios de vigilancia epidemiológica Influenza A H1N1 SEDES CBBA. 


\section{DISCUSIÓN}

Como se observan en los resultados, la batalla contra la Influenza Humana A H1N1 aún no se puede dar como vencida, debido a que en el 2014 se volvió a elevar la incidencia de casos y la reaparición de muertes asociadas a esta patología; presentando una mayor tasa de letalidad.

El comportamiento epidemiológico continúa siendo estacionario, correspondiendo la mayor incidencia al periodo de invierno y primavera en el departamento de Cochabamba; es así que la semana epidemiológica 35 de la gestión 2010 fue la que presento el mayor de número de casos positivos, seguido de las semanas epidemiológicas 25 y 38 correspondientes de la gestión 2009; similar a los reportes de García, Maritza, et al $^{12}$; quienes observaron el aumento en el número de consultas entre las semanas 21 y 30 durante el año 2009.

Si bien se observa que no existe una predilección en cuanto al sexo, pues la presentación fue similar en ambos grupos, se observa claramente que el mayor grupo de riesgo son los menores de 15 años comprendiendo más del 35\% de los casos, este aspecto es vital si consideramos que los mismos se convierten en contactos de contagio para las personas en edad escolar que cotidianamente se encuentran en sus unidades educativas; Estudios realizados por Fajardo ${ }^{13}$ encontraron el mayor porcentaje en el grupo de 10 a 19 años, con 33,9\%, el Ministerio Salud de Costa Rica ${ }^{14}$ en el grupo de 20 a 24 años; Ministerio de Salud de Argentina ${ }^{15}$ entre 15 a 64 años y la OPS $^{16}$, donde el grupo afectado fueron los adultos jóvenes, con mediana de 23 años.

La disminución de la incidencia de casos es progresiva y no existe ningún punto de inflexión brusca que pueda apoyar un solo factor para su disminución, como la introducción de la vacuna el 2010 o la implementación de estrategias de prevención de contactos como el lavado de manos en el 2009, sin embargo es llamativo que el 2014 se vuelva a elevar la incidencia, lo que nos muestra una disminución en los mecanismos de prevención primaria que probablemente fueron descuidadas ante la disminución progresiva de casos en años anteriores. (Figura 6)

Analizando el canal endémico construido con la incidencia de casos de los 5 primeros años y comparando con la última gestión evaluada (2014); podemos observar que volvimos a ingresar en la Zona de Alerta, probablemente debido a la disminución de la intensidad de los programas de prevención y promoción de la salud, dirigidas a la población general; siendo una llamada de atención para las autoridades locales para la adopción de estrategias de mitigación específicas. (Figura 6) 
Figura 6 Canal endémico de Influenza Humana A H1N1 en todas las edades por semanas epidemiológicas SEDES Cochabamba años 2009 - 2014

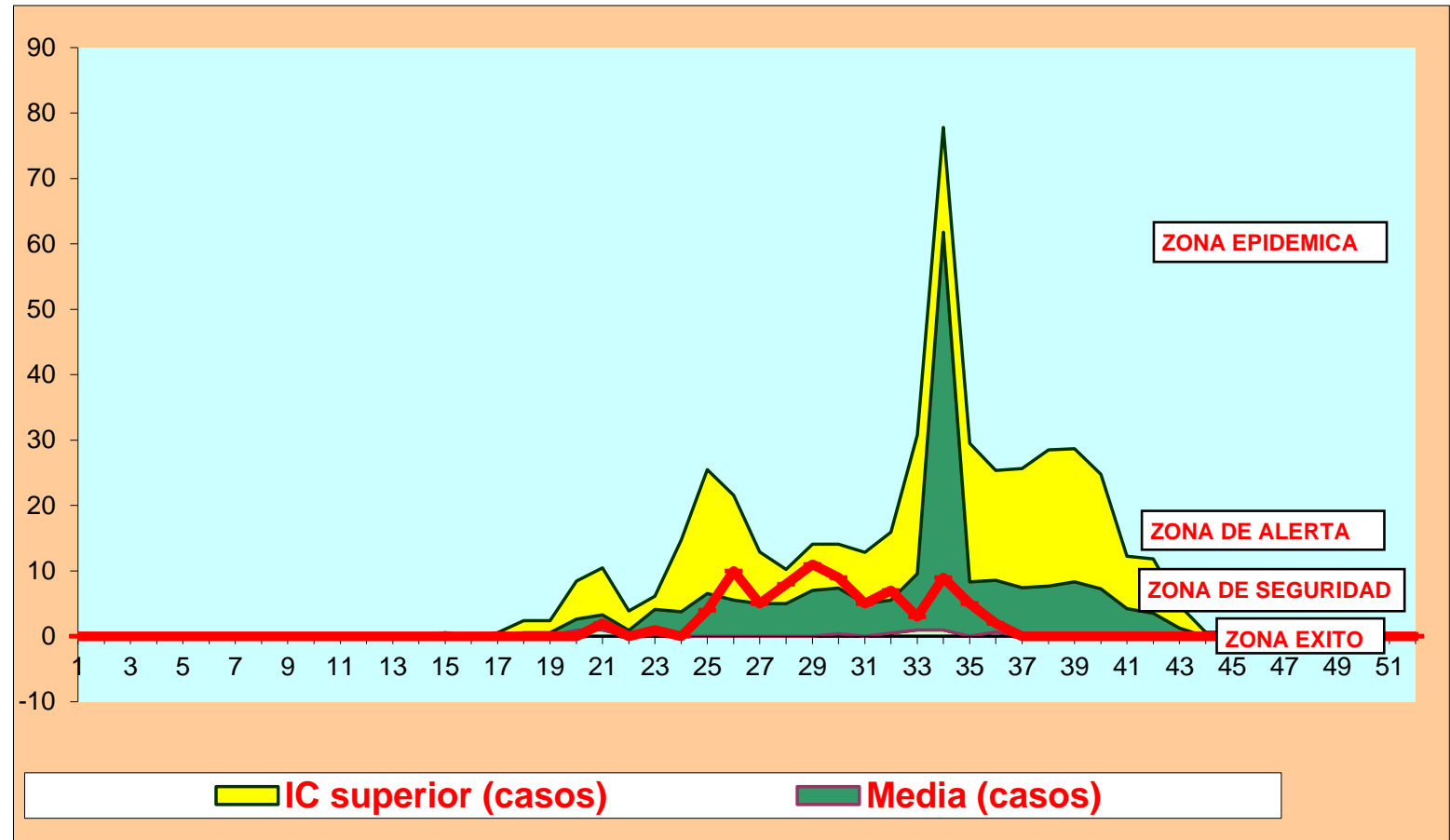

*IC: Incidencia de casos

Fuente: Elaboración propia, en base a formularios de vigilancia epidemiológica Influenza A H1N1 SEDES Cbba.

El porcentaje de casos positivos en relación a los sospechosos es mínimo, menos del 25\%, lo que nos indica una baja efectividad de los instrumentos de vigilancia epidemiológica, puesto que muchos de los pacientes negativos para H1N1 fueron tratados con antivirales antes de conocer su resultado, repercutiendo en el gasto insulso de reactivos para PCR que son de alto costo en nuestro medio.

\section{AGRADECIMIENTOS}

Al Servicio Departamental de Salud SEDES y a la ex responsable del Laboratorio de Referencia Departamental, por habernos facilitado las fichas epidemiológicas y de ese modo poder realizar el estudio respectivo, la tabulación, el análisis de datos y resultados para la elaboración del presente estudio.

\section{CONFLICTOS E INTERESES}

Los autores declaramos no tener conflictos ni intereses con el presente estudio. 


\section{BIBLIOGRAFÍA}

1. Gómez J, Munayco CV, Arrasco JC, Suarez L, Laguna-Torres VA, Aguilar PV, Chowell G, Kochel TJ. Pandemic influenza in a southern hemisphere setting: the experience in Peru from May to September, 2009. Euro Surveill. 2009;14(42):pii=19371. Available online: http:// www.eurosurveillance.org/ViewArticle.aspx?ArticleId=19371.

2. Fajardo-Dolci G, Hernández-Torres F, Santacruz J, Rodriguez J, Lamy P. Perfil Epidemiológico de la mortalidad por Influenza A H1N1 en México. Abril - Mayo 2009. Revista Salud Pública de México. Vol. 51. N 5. Disponible en URL: http://bvs.insp.mx/articulos/8/1-perfil.pdf.

3. Osores F, Gómez J, Suárez L, Cabezas C, Alave J,. Maguiña C. un nuevo virus A/H1N1, una nueva pandemia: influenza un riesgo permanente para una humanidad globalizada. Acta Med Peru. 2009; 26(2): 97-130.

4. Organización Mundial de la Salud. El nivel de alerta de pandemia de Influenza Humana se eleva de la fase 5 a la fase 6 [página de Internet]. Ginebra: OMS; 2009. [fecha de acceso: 10 de agosto de 2009] Disponible en: http://www.who.int/mediacentre/news/statements/2009/h1n1_pandemic_phase6_20090611/es/index.ht $\mathrm{ml}$

5. Dawood, F.S., et al., Emergence of a Novel swine-origin Influenza A (H1N1) virus in humans. N Engl J Med, 2009. 360(25): p. 2605-15.

6. World Health Organization. Pandemic (H1N1) 2009 update 62 [página de Internet]. Geneva: WHO; 2009. [fecha de acceso: 5 de septiembre de 2009] Disponible en: http://www.who.int/csr/don/2009_08_21/en/index.html

7. Perú, Ministerio de Salud. Situación de la Influenza AH1N1 [documento en Internet]. Lima: DGE/MINSA; 2009. [fecha de acceso: 10 de agosto de 2009] Disponible en: http://www.dge.gob.pe/influenza/AH1N1/sala/Sala_pandemia_26-07-2009.pdf

8. Perú, Ministerio de Salud. Directiva sanitaria para la atención, diagnóstico y tratamiento de Influenza en los establecimientos de salud a nivel nacional en la etapa de mitigación de la pandemia de Influenza por virus A (H1N1). Lima: MINSA; 2009.

9. World Health Organization. WHO guidelines for the collection of human specimens for laboratory diagnosis of avian influenza infection. Geneva: WHO; 2005.

10. World Health Organization. CDC protocol of realtime RTPCR for influenza A (H1N1). Geneva: WHO; 2009.

11. Instituto Nacional de Salud. Baja sensibilidad de la prueba de inmunofluorescencia indirecta para el diagnóstico de la nueva Influenza A (H1N1). Bol Inst Nac Salud. 2009; 15(7-8): 181.

12. García, M., Pedroni, E., González, C., Olea, A., Castillo, C., Cameratti, C.,\& Fasce, R. (2012). Caracterización epidemiológica y clínica de la infección por influenza A (H1N1) 2009 en San Felipe, Región de Valparaíso, Chile: Junio a agosto 2009. Revista chilena de infectología, 29(4), 382-387. 
13. Fajardo-Dolci G, Hernández-Torres F, Santacruz J, Rodriguez J, Lamy P. Perfil Epidemiológico de la mortalidad por Influenza A H1N1 en México. Abril - Mayo 2009. Revista Salud Pública de México. Vol. 51. $\mathrm{N}^{\circ}$ 5. Disponible en URL: http://bvs.insp.mx/articulos/8/1-perfil.pdf.

14. Ministerio de Salud de Costa Rica. Pandemia de Inluenza A H1N1. Actualización epidemiológica. Abril $\quad$ - Diciembre 2009. Disponible en URL http://www.ministeriodesalud.go.cr/inicio/emergencia_sanitaria/situacion_pandemia_a_h1n1_costa_ri ca.pdf.

15. Ministerio de Salud de la República Argentina. Informe de Influenza Pandémica. Semana epidemiológica $\quad \mathrm{N}^{\circ} \quad 52 . \quad$ Enero 2010. Disponible en URL. http://www.msal.gov.ar/archivos/Informe\%20SE\%2052-COM.\%20ARG-1.pdf.

16. Organización Panamericana de la Salud. Pandemia Influenza A H1N1. Octubre 2009. Disponible en URL: http://new.paho.org/pan/index.php. 